\title{
Semi-quantitative Analysis of Adenosine Perfusion Magnetic Resonance Imaging Outperforms Visual Analysis in Identifying Fractional Flow Reserve-Altered Intermediate-grade Coronary Artery Stenosis: A Pilot Study
}

Olivier Ghekiere ( $\square$ olivier.ghekiere@jessazh.be )

Jessa Hospital

Jean-Nicolas Dacher

Centre Hospitalier Universitaire de Rouen

Willem Dewilde

Imelda Hospital: Imelda vzw

Wilfried Cools

Hasselt Biostatistics and statistical Bioinformatics Center: Interuniversity Institute for Biostatistics and statistical

Bioinformatics

Paul Dendale

Jessa Hospital Campus Virga Jesse: Jessa Ziekenhuis vwz

Alain Nchimi

CHL: Centre Hospitalier de Luxembourg

Original Article

Keywords: Coronary artery stenosis, perfusion magnetic resonance imaging, adenosine, fractional flow reserve

Posted Date: February 5th, 2021

DOI: https://doi.org/10.21203/rs.3.rs-172111/v1

License: (c) (i) This work is licensed under a Creative Commons Attribution 4.0 International License. Read Full License 


\section{Abstract}

\section{Purpose}

To evaluate the diagnostic accuracy of semi-quantitative adenosine perfusion magnetic resonance imaging(MRI) to determine fractional flow reserve(FFR) $\leq 0.80$ intermediate-grade coronary stenoses as compared to visual analysis.

\section{Methods}

Forty-six patients (mean age 61 \pm 9 years;33 males) with 49 intermediate-grade stenoses underwent adenosine perfusion MRI and FFR measurement within 4 months between 2010 and 2013. Retrospective interpretation of all prospectively acquired data was performed. MRI was visually assessed by 2 experienced readers twice with one-year interval, the second time with the knowledge of the diseased artery. All myocardial enhancement maximal upslopes were evaluated distal to the coronary stenosis (=RISK) and in remote myocardium supplied by normal arteries (=REMOTE); stress subendocardial relative myocardial perfusion index (RMPI; RISK/REMOTE upslopes) was assessed in predicting FFR $\leq 0.80$ stenoses. Deep learning boosting models including all RISK and REMOTE upslopes were fitted to confirm the added value of accounting for perfusion changes in remote myocardium for FFR prediction.

\section{Results}

The average FFR value was $0.84 \pm 0.09$ and $15 / 49$ (31\%) stenoses were FFR $\leq 0.80$. Both readers had moderate accuracy (range: $36 / 49(73 \%)-38 / 49(78 \%)$ ) in predicting FFR $\leq 0.80$ stenoses, even with the knowledge of the stenosis location. At a cutoff value of 0.84 , stress subendocardial RMPI had higher accuracy (43/49(88\%)) than individual visual readings to predict FFR $\leq 0.80$ stenoses. The best FFR prediction using the boosting model occurred when accounting for REMOTE myocardial perfusion parameters, leading to diagnostic accuracy of $44 / 49(90 \%)$ for FFR $\leq 0.80$.

\section{Conclusion}

Semi-quantitative adenosine perfusion MRI accounting for stress perfusion in remote myocardium predicts FFR $\leq 0.80$ intermediate-grade coronary stenoses with a higher accuracy than individual visual analysis.

\section{Introduction}

Coronary computed tomography angiography and catheter coronary angiography poorly predict flow limitation, especially for stenoses in the intermediate-grade range (i.e. 40\%-70\% diameter reduction) $[1,2]$ that may represent up to $42 \%$ of coronary stenoses [3]. Additional functional assessment is often required to guide therapeutic management as approximately only one-third of patients with intermediate-grade stenoses suffer from ischemia and would benefit from revascularization $[4,5]$.

Invasive fractional flow reserve (FFR) measurement is the standard of reference for the functional significance (ischemia) of coronary stenoses. However, its use as a first step in intermediate-grade lesions is prevented by its invasiveness, the use of ionizing radiation, time and the costs of pressure wires [6,7]. Moreover, the use of invasive FFR varies widely depending on the practice of interventional cardiologists.

While single-photon emission computed tomography [8] and dobutamine stress echocardiography [9] have moderate accuracy $(66 \%-72 \%)$ for identifying FFR-altered (i.e. FFR $\leq 0.8)$ intermediate-grade stenoses, no study has specifically addressed this subgroup of stenoses using stress perfusion magnetic resonance imaging (MRI). Though it has a higher accuracy for the detection of myocardial ischemia as compared to other non-invasive imaging modalities [10], visual analysis of adenosine perfusion MRI in daily clinical practice may be misleading compared to FFR. Actually, MRI 
assesses perfusion defects, interrogating both the epicardial coronary artery stenosis and the downstream microvasculature, whereas the FFR value is inherently corrected for the microvascular resistance [11]. The relative myocardial perfusion index (RMPI), recently-described on MRI as the ratio of the maximal enhancement upslope distal to a coronary artery stenosis to that of a normally perfused area during stress perfusion is similar to the FFR approach [12].

As this semi-quantitative index better correlated with the FFR value than the uncorrected enhancement upslope [12], we hypothesized that RMPI could provide high diagnostic accuracy for the detection of FFR-altered intermediate coronary stenoses. Accordingly, the aim of this study was to evaluate the diagnostic accuracy of stress RMPI to determine $\mathrm{FFR} \leq 0.80$ intermediate-grade coronary stenoses as compared to individual visual analysis.

\section{Material And Methods}

\section{Patients and study protocol}

This study protocol was approved by the local institutional ethics committee, and patients provided written informed consent. Between 2010 and 2013, consecutive patients with an intermediate-grade stenosis on computed tomography angiography involving one or two major epicardial coronary vessels $>1.5 \mathrm{~mm}$ in diameter were eligible for a study requiring both catheter coronary angiography with FFR measurements and adenosine perfusion MRI within 4 months as previously reported [12]. MRI examinations were performed on a 1.5T MR scanner (Avanto, Siemens Healthineers), as previously reported [12]. In short, the examination consisted in performing stress and resting perfusion on dynamic contrast-enhancement imaging (each using $0.1 \mathrm{mmol} / \mathrm{kg}$ Gadodiamide, Omniscan ${ }^{\mathrm{O}}$ ), and late-gadolinium enhancement (LGE) in the same three short-axis positions (see the supplementary materials for more details). These prospectively acquired data were analyzed retrospectively as follows: visually twice with one-year interval, the second reading with knowledge of the diseased coronary artery; semi-quantitatively and using machine learning analysis to confirm the added value of accounting for perfusion changes in remote myocardium in predicting the FFR value.

\section{MRI analysis}

\section{Visual analysis}

Two readers (AN, JND) with more than 10-years of experience in cardiac MRI, blinded to patient's characteristics, history and coronary angiography and FFR findings, performed twice an individual visual analysis of perfusion MRI, using dedicated software (Syngo Via ${ }^{\circ}$, Siemens Health). First, splenic switch-off was qualitatively assessed to evaluate the appropriateness of the vasodilatation response after adenosine administration [13] . Myocardial ischemia was defined as stress-induced myocardial perfusion defect in the absence of LGE in the same segment, as previously reported [3]. The readers had no common training before the study and had freedom to adjust the display window level and width. In a final step, all reading discordances were solved by consensus. Twelve months after the first readings, a second round of individual and consensus visual analysis was performed by the same readers who then were provided with full knowledge of the coronary stenosis location, but still blinded to the FFR data.

\section{Semi-quantitative analysis}

Semi-quantitative analysis was performed under the supervision of an expert in cardiac MRI using dedicated software (MOCO, Syngo ViaVA30', cardiac Engine-perfusion module, Siemens Healthineers). This operator had full knowledge of 
the location of the stenosis, but was blinded to the FFR data. He performed a visual analysis using the same scheme as the 2 other readers to determine areas of myocardial perfusion defects.

As previously described [12], equally divided subendocardial (END) and subepicardial (EPI) regions of interest and timesignal intensity curves were obtained during adenosine stress in the myocardium distal to the stenosis (=RISK). When the RISK area involved more than one segment of the left ventricle representation, the myocardial segment with the greatest lateral and transmural extent of the perfusion defect was used for further measurements. Then, similar curves were obtained for a remote myocardial segment without a stenosis $\geq 40 \%$ diameter reduction on the supplying artery on QCA (=REMOTE) (Figure 1).

When no myocardial perfusion defect was visualized, the RISK segment was defined distal to the anatomic location of the coronary stenosis and the remaining steps were performed as when a perfusion defect could be visually detected. In patients with more than one intermediate-grade stenosis, each corresponding area of myocardial supply was assessed separately. Subsequently, these regions of interest were copy-pasted on the resting perfusion images. If necessary, manual correction was made to adjust the region of interest placement.

The stress subendocardial RMPI (i.e.: RISK/REMOTE mean maximal enhancement upslopes) of each stenosis was assessed for the diagnosis of FFR $\leq 0.80$ stenosis, as previously reported [12].

Maximal enhancement upslopes derived from subendocardial and subepicardial time-signal intensity curves per RISK and REMOTE areas ( $n=8$, Figure 1) for each of the stenoses were normalized to the respective left ventricle cavity enhancement maximal upslope and used for Boosting machine learning.

\section{Statistical analysis}

Statistical analyses were performed using R (version 3.2.3, with the model-based boosting package 2.6-0). Normally distributed continuous variables are expressed as mean +/- standard deviation (SD). Comparisons between continuous variables were performed using two-tailed Student t-tests, and comparisons of proportions were performed using $\chi^{2}$ tests.

A regression model was fitted to determine the best cut-off value for stress subendocardial RMPI in predicting FFR $\leq 0.80$. Then, boosting models including all semi-quantitative parameters collected in the RISK and REMOTE myocardium were used to predict FFR-related outcomes and to validate the added value of accounting for perfusion parameters in REMOTE myocardium in the prediction of these outcomes. As more extensively described in the supplementary materials, the Boosting models were assessed with the Akaike Information Criterion (AIC) value. Subsequently, the best model was optimized for a categorical outcome (i.e.: predicting FFR $\leq 0.80$ ). The diagnostic values were expressed as sensitivity, specificity, positive predictive value, negative predictive value, likelihood ratios and accuracy. The diagnostic accuracies were compared between visual readings, stress subendocardial RMPI and the boosting predictive model for FFR $\leq 0.80$, using binomial exact tests. P-values $<0.05$ were considered to express a statistically significant difference.

\section{Results}

\section{Patient and intermediate-grade coronary stenoses characteristics}

One hundred and thirty-seven patients fulfilled inclusion criteria, fifty-four were excluded because of consent refusal $(n=32)$, pacemaker $(n=1)$ and recent stress imaging $(n=21)$. Additionally, 7 patients were excluded after MRI because of 
poor image quality $(n=2)$ and a segmental transmural myocardial infarct on LGE $(n=5) ; 30$ patients were excluded after quantitative coronary angiography because actual stenosis was $<40 \%(n=12)$ or $>70 \%(n=12)$ minimal diameter reduction, because there were multiple intermediate-grade stenoses on the same artery $(n=3)$ (Figure 2 ), and $>70 \%$ stenosis on another vessel $(n=3)$. In total, 46 patients were included (mean age $61 \pm 9$ years): 33 men (mean age $59 \pm 9$ years) and 13 women (mean age $67 \pm 8$ years). The demographics and cardiovascular risk factors are given in Table 1. Three of the 46 patients (6.5\%) presented 2 intermediate-grade stenoses on distinct coronary arteries. Therefore, a total number of 49 intermediate-grade stenoses (59 $7.6 \%$ (range, $42-70 \%$ ) diameter reduction) were evaluated in this study (Table 2). The mean FFR value was $0.84 \pm 0.09$, with a range of 0.60 to $0.98 ; 31 \%(15 / 49)$ were $\leq 0.80$.

Table 1

Patient demographics and cardiovascular risk factors

\begin{tabular}{|c|c|c|}
\hline Patient characteristics & Non ischemic $(n=31)$ & Ischemic $(n=15)$ \\
\hline Age (years)* & $61 \pm 9[44-80]$ & $62 \pm 9[48-80]$ \\
\hline Ratio M/F & $22 / 9$ & $11 / 4$ \\
\hline $\mathrm{BMI}\left(\mathrm{kg} / \mathrm{m}^{2}\right) *$ & $29 \pm 5[21-39]$ & $27 \pm 3[24-35]$ \\
\hline Resting heart rate (beats per minute)* & $68 \pm 13[51-100]$ & $67 \pm 8[54-81]$ \\
\hline Family history of coronary disease & $9(29 \%)$ & $3(20 \%)$ \\
\hline Personal history of coronary disease & $3(10 \%)$ & $5(33 \%)$ \\
\hline Diabetes mellitus & $10(32 \%)$ & $2(13 \%)$ \\
\hline Current tobacco smoker & $10(32 \%)$ & $7(47 \%)$ \\
\hline Elevated blood lipid profile & $23(74 \%)$ & $13(87 \%)$ \\
\hline Systemic hypertension & $25(80 \%)$ & $8(53 \%)$ \\
\hline Agatston coronary calcium score ${ }^{\star \star}$ & 225 [139-480] & 465 [109-578] \\
\hline \multicolumn{3}{|l|}{ * Mean \pm standard deviation [range]. } \\
\hline
\end{tabular}


Table 2

Segmental topography of 49 intermediate-grade coronary artery stenosis

\begin{tabular}{|ll|}
\hline Location & $\mathrm{n}(\%)$ \\
\hline Right coronary artery & $12(24.5)$ \\
Mid segment & $3(6.1)$ \\
Distal segment & $7(14.3)$ \\
& $2(4.1)$ \\
Left main trunk & \\
Left anterior descending coronary artery & $28(57.2)$ \\
Proximal segment & $14(28.6)$ \\
Mid segment & $14(28.6)$ \\
& \\
Left circumflex coronary artery & $7(14.3)$ \\
Proximal segment & $3(6.1)$ \\
Mid segment & $2(4.1)$ \\
Distal segment & $2(4.1)$ \\
Marginal branch & $1(2)$ \\
\hline
\end{tabular}

\section{Visual analysis}

Of the 46 examinations, the spleen was not visible in one case. Splenic switch-off on stress imaging was absent in 2 cases while present in the remaining patients (43/46; 93\%). The diagnostic values of perfusion MRI for FFR $\leq 0.80$ are given on table 3 , including individual readers' visual analyses. On the first reading session, there was no significant difference in diagnostic accuracy between Reader 1 and Reader 2 (respectively 37/49, 78\% vs 36/49, 73\%); $p=0.289$ ). The consensus reading yielded a sensitivity of $73 \%(11 / 15)$ and a specificity of $85 \%(29 / 34)$ with an overall higher diagnostic accuracy compared to individual readings, although not statistically significant (all p-values $>0.05$ ). Even with the knowledge of stenosis location on the second reading, the diagnostic accuracy of the visual readings remained in the same range for individual readers and the consensus reading.

\section{Semi-quantitative analysis: RMPI and Boosting predictive models}

The values of myocardial time-signal intensity maximal upslope in RISK and REMOTE areas, normalized to the respective left-ventricle cavity enhancement upslope are summarized in Table 4, both in patients with ischemic and 
non-ischemic intermediate coronary artery stenosis. The stress subendocardial RMPI ranged between 0,57 and 1,39 $(0,81 \pm 0,17)$. Using the cutoff value of 0.84 , the stress subendocardial RMPI had higher diagnostic accuracy $(43 / 49$, $88 \%$ ) than all the visual readings to detect FFR $\leq 0.80$ intermediate-grade coronary stenoses (Table 3 ).

Bringing in information from the perfusion in remote myocardial areas on top of information in the RISK areas beyond the stenosis was suggested to improve the predictive performance (AIC from -100 to -140). The boosting model computing all semi-quantitative perfusion MRI parameters confirmed their importance with a significantly higher diagnostic accuracy (44/49,90\%) compared to all individual visual readings in predicting FFR $\leq 0.80$ stenoses, regardless of the prior knowledge of the stenosis localization (all p-values $<0.05$ ). Furthermore, this model tends to fulfill the criteria for a good diagnostic test, with positive and negative likelihood ratios of 9.82 and 0.15 , respectively (Table 3).

Table 3

Diagnostic values of visual and semi-quantitative analysis of adenosine perfusion MRI for FFR $\leq 0.80$ intermediategrade coronary artery stenoses

\begin{tabular}{|c|c|c|c|c|c|c|c|c|c|c|c|}
\hline $\begin{array}{l}\text { Intermediate } \\
\text { stenoses } \\
(n=49)\end{array}$ & TP & $\mathrm{TN}$ & FP & $\mathrm{FN}$ & Sensitivity & Specificity & PPV & NPV & LR+ & LR- & Accuracy \\
\hline $\begin{array}{l}\text { Visual } \\
\text { reading } 1 \\
\text { R1 }\end{array}$ & 13 & 24 & 10 & 2 & $\begin{array}{l}(13 / 15) \\
87 \%\end{array}$ & $\begin{array}{l}(24 / 34) \\
71 \%\end{array}$ & $\begin{array}{l}(13 / 23) \\
57 \%\end{array}$ & $\begin{array}{l}(24 / 26) \\
92 \%\end{array}$ & 2.95 & 0.19 & $\begin{array}{l}(37 / 49) \\
76 \%\end{array}$ \\
\hline $\begin{array}{l}\text { Visual } \\
\text { reading } 1 \\
\text { R2 }\end{array}$ & 7 & 29 & 5 & 8 & $\begin{array}{l}(7 / 15) \\
47 \%\end{array}$ & $\begin{array}{l}(29 / 34) \\
85 \%\end{array}$ & $\begin{array}{l}(7 / 12) \\
58 \%\end{array}$ & $\begin{array}{l}(29 / 37) \\
78 \%\end{array}$ & 3.17 & 0.63 & $\begin{array}{l}(36 / 49) \\
73 \%\end{array}$ \\
\hline $\begin{array}{l}\text { Visual } \\
\text { reading } 1 \\
\text { Consensus }\end{array}$ & 11 & 29 & 5 & 4 & $\begin{array}{l}(11 / 15) \\
73 \%\end{array}$ & $\begin{array}{l}(29 / 34) \\
85 \%\end{array}$ & $\begin{array}{l}(11 / 16) \\
69 \%\end{array}$ & $\begin{array}{l}(29 / 33) \\
87 \%\end{array}$ & 4.99 & 0.31 & $\begin{array}{l}(40 / 49) \\
82 \%\end{array}$ \\
\hline $\begin{array}{l}\text { Visual } \\
\text { reading } 2 \\
\mathrm{R} 1\end{array}$ & 8 & 30 & 4 & 7 & $\begin{array}{l}(8 / 15) \\
53 \%\end{array}$ & $\begin{array}{l}(30 / 34) \\
88 \%\end{array}$ & $\begin{array}{l}(8 / 12) \\
67 \%\end{array}$ & $\begin{array}{l}(30 / 37) \\
81 \%\end{array}$ & 4.53 & 0.53 & $\begin{array}{l}(38 / 49) \\
78 \%\end{array}$ \\
\hline $\begin{array}{l}\text { Visual } \\
\text { reading } 2 \\
\text { R2 }\end{array}$ & 10 & 26 & 8 & 5 & $\begin{array}{l}(10 / 15) \\
67 \%\end{array}$ & $\begin{array}{l}(26 / 34) \\
76 \%\end{array}$ & $\begin{array}{l}(10 / 18) \\
56 \%\end{array}$ & $\begin{array}{l}(26 / 31) \\
84 \%\end{array}$ & 2.83 & 0.44 & $\begin{array}{l}(36 / 49) \\
73 \%\end{array}$ \\
\hline $\begin{array}{l}\text { Visual } \\
\text { reading } 2 \\
\text { Consensus }\end{array}$ & 9 & 31 & 3 & 6 & $\begin{array}{l}(9 / 15) \\
60 \%\end{array}$ & $\begin{array}{l}(31 / 34) \\
91 \%\end{array}$ & $\begin{array}{l}(9 / 12) \\
84 \%\end{array}$ & $\begin{array}{l}(31 / 37) \\
84 \%\end{array}$ & 6.80 & 0.44 & $\begin{array}{l}(40 / 49) \\
82 \%\end{array}$ \\
\hline $\begin{array}{l}\text { Relative } \\
\text { myocar- dial } \\
\text { perfusion }\end{array}$ & 12 & 31 & 3 & 3 & $\begin{array}{l}(12 / 15) \\
80 \%\end{array}$ & $\begin{array}{l}(31 / 34) \\
91 \%\end{array}$ & $\begin{array}{l}(12 / 15) \\
80 \%\end{array}$ & $\begin{array}{l}(31 / 34) \\
91 \%\end{array}$ & 4.56 & 0.11 & $\begin{array}{l}(43 / 49) \\
88 \%\end{array}$ \\
\hline $\begin{array}{l}\text { Boosting } \\
\text { model }\end{array}$ & 13 & 31 & 3 & 2 & $\begin{array}{l}(13 / 15) \\
87 \%\end{array}$ & $\begin{array}{l}(31 / 34) \\
91 \%\end{array}$ & $\begin{array}{l}(13 / 16) \\
81 \%\end{array}$ & $\begin{array}{l}(31 / 33) \\
94 \%\end{array}$ & 9.82 & 0.15 & $\begin{array}{l}(44 / 49) \\
90 \%\end{array}$ \\
\hline \multicolumn{12}{|c|}{ The proportions by which the percentages were calculated are given in parentheses. } \\
\hline $\begin{array}{l}\mathrm{R} 1 \text { = reader } 1 \\
\text { magnetic res } \\
\text { predictive val } \\
\text { perfusion ind }\end{array}$ & $2=$ & der & TP & 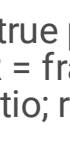 & $\begin{array}{l}\text { sitive; } \mathrm{TN}= \\
\text { tional flow } \\
\text { tive myoca }\end{array}$ & $\begin{array}{l}\text { Je negative; } \\
\text { erve; PPV = } \\
\text { ial perfusior }\end{array}$ & $\begin{array}{l}P=\text { false } \\
\text { ositive } p r \\
=\text { stress } \mathrm{s}\end{array}$ & $\begin{array}{l}\text { sitive; FN } \\
\text { ictive val } \\
\text { endocarc }\end{array}$ & $\begin{array}{l}\text { : false } \\
\text {; NPV } \\
\text { al relat }\end{array}$ & $\begin{array}{l}\text { egativ } \\
\text { negat } \\
\text { e myo }\end{array}$ & $\begin{array}{l}\text { MRI = } \\
\text { e } \\
\text { ardial }\end{array}$ \\
\hline
\end{tabular}


Table 4

Semi-quantitative subendocardial stress enhancement parameters in RISK and REMOTE myocardium during adenosine perfusion in patients with ischemic and non-ischemic intermediate coronary artery stenosis (as defined by 0.80 FFR cut-off value)

\begin{tabular}{|c|c|c|}
\hline Subendocardial stress enhancement parameter & $\begin{array}{l}\text { Ischemic (FFR } £ 0.80 \text {, } \\
n=15)\end{array}$ & $\begin{array}{l}\text { Non-ischemic (FFR > 0.80, } \\
n=31 \text { ) }\end{array}$ \\
\hline Mean maximal upslope in RISK myocardium* & $0.16 \pm 0.04[0.11-0.24]$ & $0.18 \pm 0.05[0.07-0.29]$ \\
\hline $\begin{array}{l}\text { Mean maximal upslope in REMOTE } \\
\text { myocardium* }\end{array}$ & $0.20 \pm 0.04[0.13-0.26]$ & $0.18 \pm 0.04[0.09-0.28]$ \\
\hline RMPI & $0.79 \pm 0.14[0.57-1.05]$ & $1.01 \pm 0.13[0.81-1.39]$ \\
\hline \multicolumn{3}{|c|}{$\begin{array}{l}\text { Values are given as mean } \pm \text { standard deviation [range]. } \\
\text { * Maximal upslopes are normalized by the corresponding left ventricle cavity enhancement upslope; } \\
\text { RISK = myocardium beyond stenosis; REMOTE = remote myocardium; RMPI = relative myocardial perfusion index; } \\
\text { FFR = fractional flow reserve }\end{array}$} \\
\hline
\end{tabular}

\section{Discussion}

The current study heralds important findings regarding the workup for intermediate-grade stenoses via adenosine perfusion MRI: namely the weakness of single-observer visual analyses and the importance of accounting for distant territories to better predict FFR.

Single-observer visual analysis identified FFR $\leq 0.80$ intermediate-grade stenosis with a moderate accuracy and highly variable sensitivities and specificities, likely owing to the freedom in image setting adjustment and dark-rim artifact assessment. The agreement would have been higher, but less representative of the "real life" if a pre-study training of the readers would have been organized [14]. These potential reading pitfalls suggest that the interpretation of myocardial signal abnormality depends on many more factors beyond the reader's experience.

Consensus reading resulted in higher diagnostic accuracy for FFR $\leq 0.80$ stenosis while keeping sensitivity and specificity close to the individual reader's highest levels. These results are lower than previous perfusion MRI studies [3, $15,16]$, which can be explained by the exclusive inclusion of intermediate-grade stenoses in our study. It is also in line with the reported lower sensitivity of MRI in identifying FFR $\leq 0.80$ lesions in a subanalysis of intermediate-grade stenoses from a larger series [17]. Only few studies have specifically addressed coronary flow-limitation in intermediate-grade stenoses using other non-invasive techniques such as stress dobutamine MRI [18], dobutamine stress echocardiography [9], and single-photon emission tomography $[8,19,20]$, with respective sensitivity and specificity ranges of $62 \%-95 \%$ and $69 \%-90 \%$, all confirming the challenge posed by this range of stenoses. Even the knowledge of the area-at-risk did not increase the accuracy of visual readings. Indeed, the perfusion defects induced by intermediate-grade stenoses are likely to be shallower and less extended, thus more difficult to perceive and to distinguish from subendocardial dark-rim artefacts, than those caused by high-grade stenoses [21, 22]. This implies that beyond encouraging consensus reading of perfusion MRI to mitigate the reader's perception biases, diagnostic use of MRI as a gatekeeper to predict functional significance of intermediate-grade stenoses demands improvement. Actually, visual analysis assesses only perfusion defects beyond a coronary stenosis, and does not account for perfusion in normal perfusion areas, in contrast to the FFR value [23]. As expected, the accuracy of the FFR prediction using deep-learning statistics was higher when accounting for perfusion parameters in remote, normal myocardium than when these parameters were not included. These predictive models were used as proof of concept of the added value of accounting for perfusion parameters in remote myocardium for FFR prediction. It supports the need of an 
integrative interpretation of the entire myocardium for improved perfusion MRI assessment in determining FFR $\leq 0.80$ stenoses, but is difficult to implement in clinical practice.

In this setting, the reported stress subendocardial RMPI [12] provides a simplified and more useful semi-quantitative parameter for clinical practice, with a high diagnostic accuracy to determine FFR $\leq 0.80$ intermediate-grade stenoses, in line with those of previous meta-analyses, including mainly semi-quantitative and quantitative MRI analyses [10]. This approach has also been reported in stress dynamic computed tomography perfusion showing better accuracy to identify flow-limiting stenoses than the myocardial blood flow in the area-at-risk [24]. Nevertheless, using RMPI three false-negative and three false-positive cases remained for the FFR $\leq 0.8$ cutoff, owing to image artifacts and the existence of the so-called gray-zone of FFR values (0.75-0.80) [25]. In addition, Ghekiere et al. reported in their series that all three false-negatives for RMPI exhibited splenic switch-off on adenosine imaging (i.e. did not receive appropriate adenosine vasodilatation) [12].

Our study has certain limitations including the relatively low number of patients and FFR $\leq 0.80$ stenosis. Second, the MRI studies were performed between 2010 and 2013 with an older generation equipment. Both visual and deep learning results could have been improved using a higher resolution adenosine perfusion MRI as it improves the detection of subendocardial ischemia [26]. Third, substantial amount of dropouts occurred after QCA to maintain stenoses within the intermediate-grade range and to control the possible bias related to the hemodynamic interactions between distinct coronary territories and that of successive stenosis. We nevertheless included a sufficient number of patients regarding the sample estimation for statistical significance, and approximately one-third of the intermediate-

grade stenoses had an FFR $\leq 0.80$, as reported in the literature. Larger cohorts of patients will be suitable to confirm and validate the results of our study. Finally, in spite of epicardial stenosis, several confounders may alter myocardial perfusion on MRI [27] and, therefore, its diagnostic values in predicting flow-limitation as defined by the FFR value. Systematic bias such as cardiac-phase variability of the myocardial perfusion was not taken into account [28, 29], but can be ignored as long as a single-slice frame is evaluated, as it was done in this study. Patient-related confounders inherently limit the validity of our data to a population of individuals with similar cardiovascular risk factors for microvascular disease.

In conclusion, consensus reading should be encouraged in clinical practice to improve the diagnostic accuracy of visual analysis of adenosine perfusion MRI in predicting FFR $\leq 0.80$ intermediate-grade coronary stenoses. Semiquantitative analysis using RMPI has a higher diagnostic accuracy than individual visual analysis, but further studies with larger patient samples are needed to confirm its clinical value as a gatekeeper for invasive FFR in patients with intermediate-grade stenoses.

\section{Declarations}

\section{Acknowledgements}

The authors gratefully acknowledge Isabelle Mancini and Dr. Julien Djekic of the radiology department and Dr. Michel Bellekens of the cardiology department at $\mathrm{CHC}$ Hospital, Liège, and Dr. Tim Coolen of the radiology department at University Hospital Erasme, Brussels for their assistance in acquiring the data.

\section{Funding}

This study has received funding by General Electrics Healthcare. The funding has been used to cover the costs of the adenosine perfusion MR, the contrast medium and adenosine of all included patients. 
Funding for the statistical analysis was received by Limburg Clinical Research Program (LRCP) UHasselt-ZOL-Jessa, supported by the foundation Limburg Sterk Merk, province of Limburg, Flemish government, Hasselt University, Hospital Oost-Limburg and Jessa Hospital.

\section{Conflicts of interest/Competing interests}

The authors of this manuscript declare no relationships with any companies, whose products or services may be related to the subject matter of the article.

\section{Availability of data and material}

All authors confirm that all data and materials as well as software application comply with field standards.

\section{Code availability}

NA

\section{Authors' contributions}

This study is part of a PhD project of the first author at the Hasselt University, Belgium. Experts from different sites substantially contributed to the setup and the design of the study, statistical analyses and manuscript writing. Patients were included in one site, the $\mathrm{CHC}$ hospital Liège, Belgium.

\section{Ethics approval}

The study protocol was approved by the local ethics committee (Comité d'éthique médicale N d'agrément: OM87) with reference "Etude n 09/12/473".

\section{Consent to participate}

Written informed consent was obtained from all patients to participate in this study.

\section{Consent for publication}

Written informed consent was obtained from all patients to publish their data in a journal article.

\section{Study subjects or cohorts overlap:}

Some study subjects or cohorts have been previously reported in AJR Am J Roentgenol. 2019; 212:1-8 "The value of relative myocardial perfusion at MRI for FFR-defined ischemia: a pilot study" and Int J Cardiovasc Imaging 2019;35:559-568 "Correlation of FFR-derived from CT and stress perfusion CMR with invasive FFR in intermediategrade coronary artery stenosis". See also the attached PDF. 


\section{References}

1. Tu S, Barbato E, Koszegi Z et al (2014) Fractional flow reserve calculation from 3-dimensional quantitative coronary angiography and TIMI frame count: a fast computer model to quantify the functional significance of moderately obstructed coronary arteries. JACC Cardiovasc Interv 7:768-777

2. Ghekiere O, Dewilde W, Bellekens M et al (2015) Diagnostic performance of quantitative coronary computed tomography angiography and quantitative coronary angiography to predict hemodynamic significance of intermediate-grade stenoses. Int J Cardiovasc Imaging 31:1651-1661

3. Groothuis JG, Beek AM, Brinckman SL et al (2013) Combined non-invasive functional and anatomical diagnostic work-up in clinical practice: the magnetic resonance and computed tomography in suspected coronary artery disease (MARCC) study. Eur Heart J 34:1990-1998

4. Takx RA, Blomberg BA, El Aidi $\mathrm{H}$ et al (2015) Diagnostic accuracy of stress myocardial perfusion imaging compared to invasive coronary angiography with fractional flow reserve meta-analysis. Circ Cardiovasc Imaging 8

5. Li M, Zhou T, Yang LF, Peng ZH, Ding J, Sun G (2014) Diagnostic accuracy of myocardial magnetic resonance perfusion to diagnose ischemic stenosis with fractional flow reserve as reference: systematic review and metaanalysis. JACC Cardiovasc Imaging 7:1098-1105

6. Tonino PA, De Bruyne B, Pijls NH et al (2009) Fractional flow reserve versus angiography for guiding percutaneous coronary intervention. N Engl J Med 360:213-224

7. Zhang D, Lv S, Song X, Yuan F, Xu F, Zhang M, et al (2015) Fractional flow reserve versus angiography for guiding percutaneous coronary intervention: a meta-analysis. Heart 101:455-462

8. Forster S, Rieber J, Ubleis C et al (2010) Tc-99m sestamibi single photon emission computed tomography for guiding percutaneous coronary intervention in patients with multivessel disease: a comparison with quantitative coronary angiography and fractional flow reserve. Int J Cardiovasc Imaging 26:203-213

9. Jung PH, Rieber J, Stork S et al (2008) Effect of contrast application on interpretability and diagnostic value of dobutamine stress echocardiography in patients with intermediate coronary lesions: comparison with myocardial fractional flow reserve. Eur Heart J 29:2536-2543

10. Danad I, Szymonifka J, Twisk JWR et al (2017) Diagnostic performance of cardiac imaging methods to diagnose ischaemia-causing coronary artery disease when directly compared with fractional flow reserve as a reference standard: a meta-analysis. Eur Heart J 38:991-998

11. van de Hoef TP, Meuwissen M, Escaned J et al (2013) Fractional flow reserve as a surrogate for inducible myocardial ischaemia. Nat Rev Cardiol 10:439-452

12. Ghekiere O, Dacher JN, Dewilde W et al (2019) Value of Relative Myocardial Perfusion at MRI for Fractional Flow Reserve-Defined Ischemia: A Pilot Study. AJR Am J Roentgenol:1-8

13. Manisty C, Ripley DP, Herrey AS et al (2015) Splenic Switch-off: A Tool to Assess Stress Adequacy in Adenosine Perfusion Cardiac MR Imaging. Radiology 276:732-740

14. Lubbers DD, Rijlaarsdam-Hermsen D, Kuijpers D et al (2012) Performance of adenosine "stress-only" perfusion MRI in patients without a history of myocardial infarction: a clinical outcome study. Int J Cardiovasc Imaging 28:109115

15. Bettencourt N, Chiribiri A, Schuster A et al (2013) Cardiac magnetic resonance myocardial perfusion imaging for detection of functionally significant obstructive coronary artery disease: a prospective study. Int J Cardiol 168:765773

16. Watkins S, McGeoch R, Lyne J et al (2009) Validation of magnetic resonance myocardial perfusion imaging with fractional flow reserve for the detection of significant coronary heart disease. Circulation 120:2207-2213 
17. Ebersberger U, Makowski MR, Schoepf UJ et al (2013) Magnetic resonance myocardial perfusion imaging at 3.0 Tesla for the identification of myocardial ischaemia: comparison with coronary catheter angiography and fractional flow reserve measurements. Eur Heart J Cardiovasc Imaging 14:1174-1180

18. Gebker R, Frick M, Jahnke $C$ et al (2012) Value of additional myocardial perfusion imaging during dobutamine stress magnetic resonance for the assessment of intermediate coronary artery disease. Int J Cardiovasc Imaging 28:89-97

19. Rieber J, Jung P, Erhard I et al (2004) Comparison of pressure measurement, dobutamine contrast stress echocardiography and SPECT for the evaluation of intermediate coronary stenoses. The COMPRESS trial. Int $J$ Cardiovasc Intervent 6:142-147

20. Hacker M, Rieber J, Schmid R et al (2005) Comparison of Tc-99m sestamibi SPECT with fractional flow reserve in patients with intermediate coronary artery stenoses. J Nucl Cardiol 12:645-654

21. Shehata ML, Basha TA, Hayeri MR, Hartung D, Teytelboym OM, Vogel-Claussen J (2014) MR myocardial perfusion imaging: insights on techniques, analysis, interpretation, and findings. Radiographics 34:1636-1657

22. Coelho-Filho OR, Rickers C, Kwong RY, Jerosch-Herold M (2013) MR myocardial perfusion imaging. Radiology 266:701-715

23. De Bruyne B, Baudhuin T, Melin JA et al (1994) Coronary flow reserve calculated from pressure measurements in humans. Validation with positron emission tomography. Circulation 89:1013-1022

24. Yang J, Dou G, He B et al (2020) Stress Myocardial Blood Flow Ratio by Dynamic CT Perfusion Identifies Hemodynamically Significant CAD. JACC Cardiovasc Imaging 13:966-976

25. Johnson NP, Toth GG, Lai D et al (2014) Prognostic value of fractional flow reserve: linking physiologic severity to clinical outcomes. J Am Coll Cardiol 64:1641-1654

26. Motwani M, Maredia N, Fairbairn TA et al (2012) High-resolution versus standard-resolution cardiovascular MR myocardial perfusion imaging for the detection of coronary artery disease. Circ Cardiovasc Imaging 5:306-313

27. Rieber J, Huber A, Erhard I et al (2006) Cardiac magnetic resonance perfusion imaging for the functional assessment of coronary artery disease: a comparison with coronary angiography and fractional flow reserve. Eur Heart J 27:1465-1471

28. Motwani M, Kidambi A, Uddin A, Sourbron S, Greenwood JP, Plein S (2015) Quantification of myocardial blood flow with cardiovascular magnetic resonance throughout the cardiac cycle. J Cardiovasc Magn Reson 17:4

29. Nchimi A, Mancini I, Broussaud TK (2014) Influence of the cardiac cycle on time-intensity curves using multislice dynamic magnetic resonance perfusion. Int J Cardiovasc Imaging 30:1347-1355

\section{Figures}



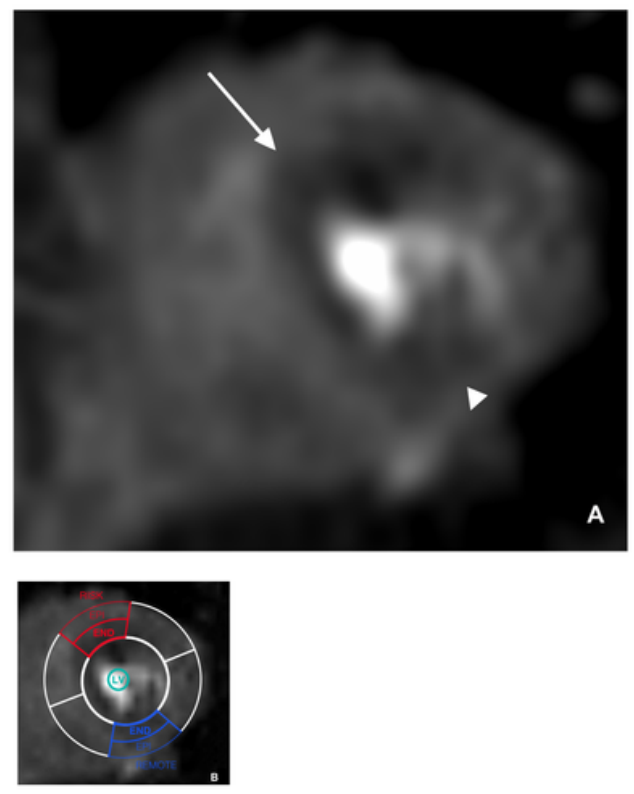
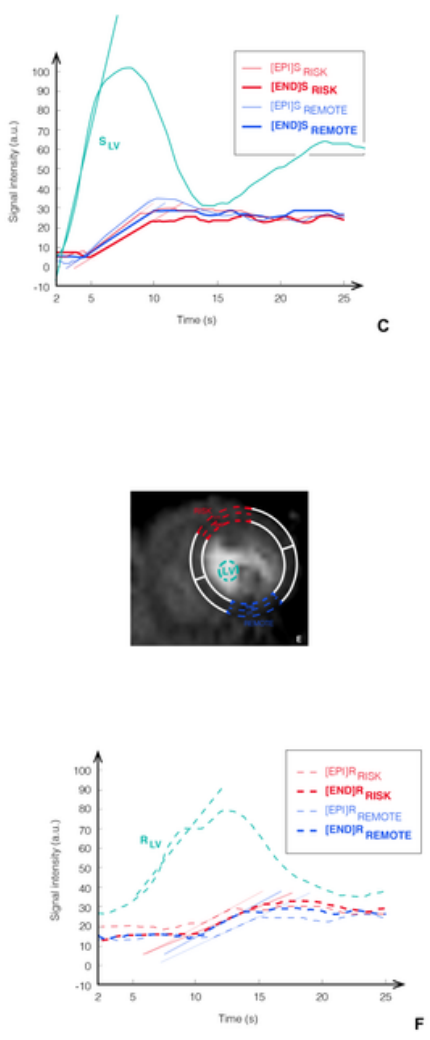

\section{Figure 1}

Semi-quantitative myocardial perfusion magnetic resonance imaging analysis Detailed steps for semi-quantitative perfusion magnetic resonance imaging (MRI) analysis in a 69-year-old patient with intermediate-grade stenosis of the mid portion of the left anterior descending artery on both coronary computed tomography angiography and catheter coronary angiography (not shown). Peak myocardial enhancement on adenosine perfusion MRI showed a septal and anterior wall mid-left ventricular area of low signal intensity (white arrow, segment 7 in figure $1 \mathrm{~A}$ ) in the area-at-risk (RISK), whereas the remote area (REMOTE) (arrowhead, segment 10 in figure $1 \mathrm{~A}$ ) and both areas on rest perfusion (figure 1D) were homogenously enhanced. Note the more systolic phase during stress perfusion, while the rest perfusion was performed during the diastolic phase of the cardiac cycle. No abnormal enhancement was present on late-enhancement imaging (not shown). Equally divided subendocardial (bold lines, END) and subepicardial (thin lines, $\mathrm{EPI}$ ) regions of interest are drawn in the RISK (red color) and REMOTE segments (blue color) after outlining the endocardial and epicardial borders of the myocardium during maximal hyperemia (Figure 1B). The same indicators are present (dashed lines, same colors) on the rest peak myocardial enhancement images (figure 1E). After extending these regions of interest to the whole frames, corresponding time-signal intensity curves and the maximal upslope value of the contrast enhancement were obtained (Figures 1C and 1F). RISK = myocardium beyond stenosis; REMOTE = remote myocardium; $[E N D]$ = subendocardial; $[E P I]$ = subepicardial; $R=$ rest imaging; $S=$ adenosine stress imaging 


\section{Image not available with this version}

\section{Figure 2}

Study flowchart CCTA = coronary computed tomography angiography; CCA = catheter coronary angiography; QCA = quantitative coronary angiography; FFR = fractional flow reserve; $\mathrm{MRI}=$ magnetic resonance imaging.

\section{Supplementary Files}

This is a list of supplementary files associated with this preprint. Click to download.

- Supplementalmaterials.pdf 